Rohrbaugh JW, Gaillard AWK (1983): Sensory and motor aspects of contingent negative variation. In Gailland AWK, Ritter W (eds), Tutorials in ERP Research: Endogenous Components. Amsterdam: Elsevier, pp 269-311.

Swerdlow NR, Koob GF (1987): Dopamine, schizophrenia, mania and depression: Toward a unified hypothesis of cortico-striato-pallidothalamic function. Behav Brain Sci 10:197-245.

Tyrer P, Owen RT, Cicchetti DV (1984): The brief scale for anxiety: A subdivision of the comprehensive psychopathological rating scale. J Neurol Neurosurg Psychiatry 47:970-975.

Van Praag HM, Korf J, Puite J (1970): 5-Hydroxyindole- acetic acid levels in the cerebrospinal fluid of depressive patients treated with probenecid. Nature 225:1259-1260.

Van Praag HM, Kahu RS, Asnis GM, et al (1987): Denologization of biological psychiatry or the specificity of 5-HT disturbances in psychiatric discrders. $J$ Affective Disord 13:1-8.

Walter WG, Cooper R, Aldridge VJ, McCallum WC, Winter A (1964): Contingent negative variation: An electric sign of sensori-motor association of expectancy in the human brain Nature 203:380-384.

Widlöcher D (1983): Psychomotor retardation: Clinical, theoretical and psychometric aspects. Psychiat Clin North Am 6:27-40.

\section{Depression after Cyproheptadine: MAO Treatment}

\section{To the Editor:}

Cyproheptadine has been reported to be effective in the treatment of anorgasmia induced by the administration of tricyclic antidepressants (Sovner 1984; Steele and Howell 1986), monoamine oxidase inhibitors (MAOls) (DeCastro 1985), or fluoxetine (McCormick et al 1990). It has been postulated that cyproheptadine's efficacy in treating this symptom is caused by the blockade of serotonin receptors.

The administration of cyproheptadine for the treatment of antidepressant-induced sexual dysfunction has recently been associated with a recurrence of depressive symptomatology in a series of three patients treated with fluoxetine (Feder 1991), as well as with the reversal of therapeutic benefit in two patients with bulimia nervosa, also treated with fluoxetine (Goldboom and Kennedy 1991).

We report here a case of recurrence of depressive symptoms after administration of cyproheptadine in a patient who received sull therapeutic benefit from treatment with phenelzine.

Mr. C. is a 37-year-old man who presented for diagnosis and treatment of chronic depressive symptomatology. Upon evaluation, he was severely depressed, with a blunted affect, as well as mood irritability, and a history of chronic impulsive selfinjurious behavior, usually during the periods of more severe depression. A 17-item Hamilton Depression Rating Scale (HDRS) score of $\mathbf{3 8}$ was obtained on initial evaluation. Although no actual suicide attempts were reported, he described almost constant suicidal ideation, which he resisted by increasing his physical activity until exhaustion.

During the year prior to evaluation, he had been attending weekly outpatient psychotherapy. Concomitant with the psychotherapeutic intervention, several medication trials had been attempted, including desipramine, imipramine and nortriptyline, without relief of depressive symptoms. Trazodone was reported of limited benefit, with a mild reduction in depressive symptomatology, but severe sedation and orthostatic hypotension necessitated discontinuation of this agent. A trial of fluoxetine significantly reduced symptomatology after 6 weeks, but was also poorly tolerated due to severe agitation and anxiety.

In addition to a referral for cognitive-behavioral therapy, phenelzine was initiated, to a maximum dose of $75 \mathrm{mg}$ per day. After 5 weeks on this regimen, his depressive symptomatology remitted (HDRS score $=4)$. Suicidal ideation and self-injurious behavior, as well as the demanding, impulsive, and irritable style noted in the initial presentation, were also markedly diminished.

Concomitant with the resolution of his depressive symptomatology, the patient reported difficulties in sexual activity, with delayed ejaculation that later progressed to anorgasmia. Treatment with cyproheptadine was initiated at a daily dose of $4 \mathrm{mg}$ in an attempt to reduce his sexual dysfunction. Within 3 days of initiating this medication, nearly complete recurrence of depressive symptomatology was observed. No improvement of anorgasmia was reported 
by the patient. Discontinuation of cyproheptadine promptly reduced his depressive symptoms (HDRS scores decreased from 22, 5 days after cessation of cyproheptadire, to 6,12 days after discontinuing treatment). At the present time, the patient reports a moderate degree of delayed ejaculation, although he is no longer anorgasmic.

We report here an instance of recurrence of depressive symptomatology 3 days after the administration of cyproheptadine in a patient who had responded fully to treatment with the MAOI phenelzine. This phenomenon has been reported previously, in a similarly rapid time course (few hours to 4 days), in three patients responsive to the serotonin-reuptake blocker, fluoxetine (Feder 1991). Cyproheptadine may lead to a reversal of clinical benefit when administered for the rreatment of antidepressant-induced anorgasmia. Close observation of patients treated with this regimen is suggested.

John Kar Zubieta Mark A. Demitrack
Department of Psychiatry

University of Michigan Medical Center

Ann Arbor, Michigan

\section{References}

DeCastro DM (1985): Reversal of MAOI-induced anorgansmia with cyproheptadine. Am J Psychiatry 142:783.

Feder R (1991): Reversal of antidepressant activity of fluoxetine by cyproheptadine in three patients. J Clin Psychiatry 52:163-164.

Goldboom DS, Kennedy SH (1991): Adverse interaction of fluoxetine and cyproheptadine in two patients with bulimia nervosa. J Clin Psychiatry 52:261-262.

McCormick S, Olin J, Brotman AW (1990): Reversal of fluoxetine-induced anorgasmia by cyproheptadine in two patients. J Clin Psychiatry 51:383-384.

Sovner R (1984): Treatment of tricyclic antidepressant-induced orgasmic inhibition with cyproheptadine. J Clin Psychopharmacol 4:169.

Steele TE, Howell EF (1986): Cyproheptadine for imipramine-induced anorgasniia. J Clin Psychopharmacol 6:326-327.

\section{Sodium Valproate Augmentation of Fluoxetine or Fluvoxamine Effects}

To the Editor:

Fontaine et al (1991) described the addition of lithium to fluoxetine in the treatment of refractory depression. This is likely to be a major advance if lithium augments the action of fluoxetine without producing a pott ntially dangerous hyperserotonin syndrome (CSM $19 \& 9)$. For cases in whom there are contraindications to the use of lithium carbonate, the introduction of sodium valproate may be considered. The use of sodium valproate in the treatrnent of affective illness has been previously described (Emrich et al 1985), but it also appears to have an augmenting effect on the specific serotonin reuptake inhibitors fluoxetine and fluvoxamine. Two cases are described in some detail.

\section{Case 1}

A 57 -year-old woman was referred with a 2 month history of panic attacks and depression with weight loss, sleep disturbance, and feelings of guilt. The general practitioner treated the woman with imipramine, which caused a rash, and benzodiazepines. Treatment with clomipramine, then with clomipramine and tryptophan, was not completely effective and she was unable to stop the diazepam because of continuing feelings of anxiety. There was also a severe tremor so these drugs were gradually withdrawn. A course of electrconvulsive therapy (ECT) helped temporarily but was followed by a rapid deterioration. Eighteen months after initial referral, fluoxetine was started and was increased gradually to $20 \mathrm{mg}$ TID, and nifedipine, which might have been maintaining the depression, was discontinued. The patient was discharged on fluoxetine 60 mg mane only, but 3 weeks later reported severe depression, wakening with panic at 5:00 A.M., diurnal variation of mood, and poor appetite. Fluoxetine was reduced to $20 \mathrm{mg}$ mane, sodium valproate was added, and 4 weeks later there was a marked improvement. Six weeks after the introduction of valproate the patient was completely free frum pan- 